Notre Dame Law School

NDLScholarship

Natural Law Forum

$1-1-1957$

\title{
Contemporary Ethical Theories and Jurisprudence
}

George Nakhnikian

Follow this and additional works at: http://scholarship.law.nd.edu/nd_naturallaw_forum

Part of the Law Commons

\section{Recommended Citation}

Nakhnikian, George, "Contemporary Ethical Theories and Jurisprudence" (1957). Natural Law Forum. Paper 17.

http://scholarship.law.nd.edu/nd_naturallaw_forum/17

This Article is brought to you for free and open access by NDLScholarship. It has been accepted for inclusion in Natural Law Forum by an authorized administrator of NDLScholarship. For more information, please contact lawdr@nd.edu. 


\section{GONTEMPORARY ETHICAL THEORIES}

\section{AND JURISPRUDENCE \\ George Nakhnikian}

Four TYPES of ethical theory have been the ones most heatedly debated among analytic philosophers since the appearance in 1903 of G. E. Moore's Principia Ethica. Each type has certain consequences for jurisprudence. This essay describes the essential features of the theories and points out some of the readily discernible consequences.

For the sake of clarity, I shall explain how I am using the terms 'jurisprudence' and 'ethical theory' and make some remarks concerning the relevance of ethics for jurisprudence.

I have adopted Julius Stone's definition of 'jurisprudence' and his threefold division of jurisprudence into analytical, ethical, and sociological. "Jurisprudence," writes Stone, "is the examination of law in the light of other disciplines than the law." 1 The following three main questions may be asked concerning the law:

(1) What are the definitions and premises which will permit us to view the contents of the legal order (i.e., the legal propositions or precepts or any part of them) as a logically (in the syllogistic sense) self-consistent system? [Analytical Jurisprudence.]

(2) What is the ideal, or what are the ideals, to which we ought to seek to make the legal order conform? What ought it to do for the men whose conduct it governs? [Ethical Jurisprudence.]

(3) What are the actual effects of the law upon the attitudes and behavior of the men whose conduct it governs, and what are the effects of these attitudes and behavior upon the legal order? [Sociological Jurisprudence.] ${ }^{2}$

Of these three subdivisions of jurisprudence, only the first and the second are directly affected by ethical theory.

Contemporary ethics in turn divides into ethical theory and normative ethics. Ethical theory concerns itself with such questions as these: What is the semiotical status (roughly, the "meaning") of ethical words such as 'good,' 'right,' 'duty,' 'obligation'? Can any one of such terms be an adequate primitive for defining the rest? Can ethical terms be defined in nonethical

1. Juluus Stone, Thr Province and Function of LAw 25 (Harvard, 1950).

2. Id. at $30-43$ and passim. 
terms? Are ethical sentences judgments capable of being true or false? Are they, like the statements in the field of the natural sciences, confirmed or "disconfirmed" by the evidence obtained from experimentation and observation? These and similar questions which may be asked in ethical theory are questions about the typical meanings or standard functions of, and logical connections among, certain words and sentences. They are not questions about what we ought to do or what we ought to value.

Questions about what we ought to do and value are normative questions. Traditionally such questions have been regarded as belonging to normative ethics or moral philosophy. Normative ethics is that branch of philosophy which seeks to discover, justify, and communicate normative principles (rules of conduct, rules enjoining certain kinds of disposition, etc.) which are objective. $^{3}$ These are some familiar examples of purportedly objective principles about values and obligations: Happiness is the highest good; Truth telling is an unconditional duty; Whenever a conflict exists between one's prima facie obligation to keep a promise and his prima facie obligation to relieve suffering, the latter obligation is his actual duty. Whether or not a normative principle is objective and in what sense objective is one of the problems of ethical theory. Those who deny that normative ethics is a theoretical investigation (i.e., an investigation capable of yielding objective conclusions) do not deny that we utter moral judgments. What they in effect deny is that such utterances are objective. The issues here involved will be explained below.

Any conclusion reached regarding the objectivity of normative utterances has certain consequences for the status and procedures of ethical jurisprudence.

If we accept a philosophy which countenances normative ethics, in our ethical jurisprudence we shall have to look for philosophically established norms by which to criticize legal norms. This is a logical consequence of our definitions of 'jurisprudence' and 'normative ethics.' The appeal to natural law as the justifying ground of legal rules is a case in point. Natural law theories seek to prove (a) that normative ethics is a theoretical discipline, a kind of science, and (b) that from purely factual premises, be they scientific or metaphysical, it is possible to come to ethical conclusions. It is held that the factual premises are not merely psychologically persuasive. They are logical reasons for accepting the ethical conclusions. Every one of the ethical

3. The notion of objectivity is complicated by the many senses of the word "objective." For our purposes, we shall take it that a principle is objective if, and only if, there are justifying grounds for adopting it. Moreover, those justifying grounds must entitle us to say truly that the principles they justify are criteria for criticizing the ethical validity of a given moral code. For, unless this second condition is satisfied, we can criticize principles only within a moral code. We can never criticize a moral code as a whole. 
theories that we shall describe presently accepts or rejects one or both of these closely related themes of natural law theories. Naturalism accepts both. It takes the passage from the factual to the ethical to be deductive, provided certain naturalistic definitions (what these are will be explained below) are conjoined to the factual premises. Intuitionists and Neo-Kantians admit (a) but deny (b). All varieties of non-cognitivism deny (a); and all but one deny (b). The exception is that group of Oxford philosophers who take the passage from the factual to the ethical to be neither deductive nor inductive. They regard the logic of moral reasoning as sui generis. A paradigm of this position is found in Stephen Toulmin's An Examination of the Place of Reason in Ethics. The implications of Oxford ethical theories for natural law will be discussed in some detail below. This initial and summary statement is intended to illustrate how crucially ethical jurisprudence is affected by disputes at the level of ethical theory.

If normative ethics is rejected, we have two alternatives regarding the questions which delimit the province of ethical jurisprudence.

The first alternative is to change the question: "What are the ideals to which we ought to make the legal order conform?" to "What are the ideals to which we in fact make the legal order conform?" This procedure eliminates ethical jurisprudence in favor of sociological jurisprudence. The interesting theoretical questions now are not requests for a "rational," "cognitive," "objective," "universal and necessary" demonstration of the validity of some legal norms in contrast to others. They are, rather, requests for the causal explanation of legal norms by appeal to their source in such factors as the will of the electorate or the dynamics of individual and social psychology or autonomous cultural determinants. These are empirical, not philosophical, matters. This is in effect the position of logical positivism in philosophy, and legal positivism in the law.

The second alternative is to change not the question but the logical status of its answer. The champions of normative ethics look upon normative rules as, through and through, valid or invalid. It is possible to deny this while agreeing with friends of normative ethics (a) that the normative question of ethical jurisprudence is meaningful and irreducible to the sociological question of the first alternative, (b) that the problem of validating legal norms is theoretically interesting and irreducible to causal explanation, and (c) that it is logically impossible to validate legal norms without recourse to other norms. Within the framework of the second alternative, then, the issue between the friends and foes of normative ethics is not whether or not legal norms require other norms for their validation. The issue is over the objectivity of the validating norm. Is it a judgment (i.e., an assertion, 
something capable of being true or false) pure and simple, or is it partly a judgment, partly something else, or is it in no way a judgment? The critics of normative ethics say that norms are not judgments; pure and simple, hence they are not philosophical judgments, pure and simple. Therefore, there are no answers to the questions of ethical jurisprudence that are simpliciter, philosophically true or false, valid or invalid.

To sum up, ethical theory is needed whenever a question arises concerning the legitimacy of normative ethics. The status of normative ethics, in turn, affects the status of ethical jurisprudence. If normative ethics is admitted, ethical jurisprudence must find the answers to its questions in philosophy. If normative ethics is rejected, according to the first alternative the questions of ethical jurisprudence are badly put, unanswerable or senseless, or their answers are false. According to the second alternative, their answers are not objective.

Ethical theory has consequences also for analytical jurisprudence. A common neutral ground between ethical theory and analytical jurisprudence is the study of normative locutions. Are normatives reducible to descriptives? Is the word 'normative' in 'ethically normative' and 'legally normative' merely a homonym? Or are legal and ethical locutions, qua normative, alike? The ethical theorist has no monopoly on these problems. A student of analytical jurisprudence could with equal propriety seek their solution. This means that ethical theorists could learn from the work of analytical jurists, and conversely. It is the converse relation that interests us here.

Having introduced our topic with some terminological assumptions and with some general remarks on the relation of ethics to jurisprudence, we now turn to describing the essential features of the currently most influential types of ethical theory and their consequences for ethical and analytical jurisprudence.

Contemporary ethical theories may be classified into four types: naturalism, intuitionism, non-cognitivism, Neo-Kantianism. ${ }^{4}$

The fundamental theses of naturalism are these. (1) Ethical sentences are genuine judgments (capable of being true or false). (2) The truth or falsehood of ethical sentences is established by methods of experimentation and observation characteristic of the natural sciences. (3) Ethical words are definable in terms of words that refer to scientifically discriminable

4. See Frankena, Moral Philosophy at Mid-Century, 60 Philosophrcal Revizw 44 (1951). 
properties of objects or states of affairs. ${ }^{5}$ These are the only articles on which there is universal agreement among naturalists. In matters of detail there are almost as many disagreements as there are individual naturalists. Intuitionists ${ }^{6}$ assert (1), but deny (2) and (3). Non-cognitivists include the logical positivists, ${ }^{7}$ C. L. Stevenson-who must be listed separately because he resists easy classification-and the contemporary Oxford philosophers of ordinary language. Among the positivists, Stevenson, and the Oxford philosophers, the agreements are more significant than the disagreements. The logical positivists and Oxford philosophers deny (1), (2), and (3), but for different reasons and with different implications. Stevenson denies (1), (2), and (3), but not without important qualifications. The Neo-Kantians cannot be easily characterized with reference to (1), (2), and (3). I shall present, as a paradigm of their position, certain aspects of C. I. Lewis's views.

Let us now try to amplify the foregoing characterizations. The naturalist's joint assertion of (1), (2), and (3) amounts to saying that normative ethics is an empirical study. The usual procedure is to begin by trying to show that (3) is true. This is the crucial step. For if $(3)$ is granted, then (2) follows from it, and (1) follows from (2). Suppose, for example, we define ' $\mathrm{X}$ is intrinsically good' as ' $\mathrm{X}$ is desired for its own sake by a normal observer'-where by 'a normal observer' we mean an observer whose factual judgments are reliable - and define ' $\mathrm{X}$ is extrinsically good' as ' $\mathrm{X}$ is causally necessary for realizing the intrinsically good.' Next, if we assume that psychologists can (actually or potentially) tell when an observer is desiring something for its own sake, and if we assume that we have rough and ready but workable operational criteria for deciding the normality of an observer and of the conditions of observations, then questions as to de facto intrinsic goods and extrinsic goods become empirical. Thus, value judgments turn out to be verifiable. Building on this foundation, one might then define 'ought,' perhaps, in terms of 'good' (e.g., 'X ought to be done' meaning ' $\mathrm{X}$ is a duty' might be construed as ' $\mathrm{X}$ is conducive to the realization of

5. Thus we can explain a naturalistic definition as one which satisfies (3). There is a wider sense of the word "naturalistic" than the one here used. This is the sense defined by C. D. Broad in Some of the Main Problems of Ethics, 21 Prirosophy 99 (1946). In this sense, any ethical theory is naturalistic if it claims to define ethical words by nonethical words, scientific or otherwise, and/or claims to derive, deductively or inductively, ethical sentences from nonethical sentences, scientific or otherwise. In this sense of the word, a theological ethics which defines ' $X$ is good' as ' $X$ is what God wills' is naturalistic. According to the usage here adopted, however, John Dewey is an ethical naturalist; a theological ethical theorist is not. We could equally well render this sense of "ethical naturalism" by the label "ethical empiricism."

6. E.g., A. C. Ewing, C. D. Broad, G. E. Moore, Sir David Ross.

7. E.g., A. J. Ayer, R. Carnap. 
maximum good'), so that statements about duties would also turn out to be empirically verifiable.

If naturalistic ethical theories are correct, their first consequence is that normative ethics is possible. If ethical judgments are cognitive and empirical, they can be discovered, justified, communicated by the same devices as those used in the physical and social sciences. Reasonable men can debate matters of moral principle objectively, antecedently assured that in time agreement can be achieved on what is true or false in morals. For even a general first principle of normative ethics such as the principle of utility is put forth by some naturalistic moral philosophers not as an arbitrary axiom nor as a selfevident truth, but as an empirically justifiable "hypothesis." Being a first principle, the utility principle cannot be deduced from a more basic principle. But there may be other ways of empirically "justifying" first principles. "Is the principle of utility susceptible of any direct proof?" asks Bentham. "It should seem not: for that which is used to prove everything else, cannot itself be proved: a chain of proofs must have their commencement somewhere. To give such proof is as impossible as needless." 8 Nevertheless, the utility principle can in some manner be justified. A moral principle has to be practical; it has to be capable of determining and guiding conduct by resolving conflicts among less general principles. Bentham's argument in favor of the utility principle simply comes down to this. Since human beings are (i) motivated by desire for pleasure and aversion from pain and (ii) capable of unselfish conduct, the Principle of Utility is the only principle which can function as an ultimate norm. There is no other principle which could be ultimate and practical. ${ }^{9}$ More generally speaking, Bentham's "proof" may be phrased as follows: Given the data of morality, including moral disagreements and the disputes they engender, the utility principle is the most useful "hypothesis" so far proposed for systematizing the data of morality coherently among themselves and in relation to nonmoral facts, as well as for providing a psychologically realistic regulative principle for the undogmatic and reasonable discussion of moral disagreements.

Whether Bentham's defense is cogent or not is not here in question. What interests us is (1) the considered opinion of a representative naturalistic moral philosopher that first principles of conduct can be justified; and (2) the proposed manner of justification, which is very different from the a priori

8. J. Bentham, Introduction to the Principles of Morals and Legislation c. 1, para. 11.

9. Cf. Hall, The "Proof" of Utility in Bentham and Mill, 60 Etrics, No. 1 (Oct., 1949), esp. pp. $13 \mathrm{ff}$. Also my Intrinsic Good and the Ethical Ought, 51 Journal op Philosopmy 788 (1954), esp. pp. 792-94. Also my Value and Obligation in Mill, 62 Eтuics 33 (1951). 
Kantian method of transcendental deduction. ${ }^{10}$ Since naturalistic ethical theory countenances normative ethics, naturalistic ethical jurisprudence would have at its disposal a set of objective and empirically arguable moral principles. By appealing to these moral principles questions as to what sorts of laws should exist could be answered objectively and by empirical methods of validation. There would be no need for appeals to divine law, self-evident moral intuitions or ultimately unreasoned and arbitrary decisions. This does not mean that a first principle, such as that of utility, would be able to settle all moral issues in detail. According to at least one commentator, Bentham himself offers his principle of utility as a "hypothesis which does not dogmatically settle all concrete ethical issues but opens a critical discussion of them."11

Moreover, the analytical jurist can argue that if moral terms can be defined in empirical terms, so can legal terms. For the particular hurdle naturalism has to clear is the normativeness of ethical terms. If naturalism can define ethical terms by empirical terms, it can, a fortiori, do the same thing with legal terms. The one additional premise we need to establish is that whatever their differences, legal and moral terms are alike normative.

At this stage it would be appropriate to explore the possibility of codifying legal systems. By codification we are to understand not the legal practice of writing law into documents but the logical procedure of trying to make explicit the formal structure of the law. This, in turn, depends on one's conception of law. If the conception is Austinian or Kelsenite, the analytical jurist will try to do for the law what Whitehead and Russell did for mathematics. In the Principia Mathematica they showed that all mathematics is deducible, in accordance with certain rules of inference, from a finite number of axioms whose undefined terms are a finite number of logical words and the relation of class membership. The corresponding task for the law, if it is naturalistically analyzed, would be to take a legal domain, e.g., English law, and to show that a set of mutually consistent axioms logically imply all (or perhaps only restricted classes of) the statements of the domain, and that the undefined (primitive) terms of those axioms, apart from the logical ones, are empirical. The former accomplishment would prove that the axioms in question delimit the domain of English law. The latter accomplishment would prove that English law can be naturalistically analyzed. At the outset, it may not be assumed that the same logical structure will satisfy different

10. An account of the nature of Kant's transcendental deduction is to be found in $H$. J. Paton, The Categorical Imperative 27-29 (Chicago, 1948). Kant's manner of justifying moral principles is nonempirical. Another nonempirical way of arguing for the validity of moral principles is C. I. Lewis's. See below.

11. D. Baumgardt, Bentham and the Ethics of Today 147, 529, 530 (Princeton, 1952). 
legal systems. For example, the logical structure of English law may not coincide (be isomorphic) with that of German law. One would first have to codify logically restricted legal domains and then look to see whether or not the logical structures they exhibit have anything in common.

There are serious reasons for doubting that legal domains are capable of logical axiomatization in the way that mathematics is. There are competent scholars who aver that by its nature the law is disjointed, loosely knit and "unfinished," in ways that mathematics is not. At any rate, no one to date has attempted a rigorous axiomatization of legal domains. But the issues involved have not been fully explored; and until they are, the question must remain open. This is one of the principal problems of analytical jurisprudence.

Naturalism, however, has not gone unchallenged. In a happy metaphor, Professor Rice 12 describes how blows have been showered on it from overhead by supernaturalistically inclined philosophers, from the Right by the intuitionists (including Moore, Broad, Ross, Ewing), and from the Left by the non-cognitivists (Carnap, Ayer, Stevenson, and the Oxford ordinary language philosophers).

The opposition has challenged naturalism at the first step, the step of defining ethical terms in nonethical terms. The challenge has been salutary, having forced naturalists to work hard at certain logical and semiotical issues which they had more or less slurred over. But my aim is not to tell that part of the story, except as it has to be told while we are about our main business, namely, to report on these conflicting contemporary ethical theories and what they entail for jurisprudence.

The intuitionists have criticized naturalistic definitions of ethical terms on the ground that in such definitions the defining phrase does not carry the normative force of the term being defined. The term ' $\mathrm{X}$ is good' or ' $\mathrm{X}$ is right' has a normative force which, they say, does not appear in ' $\mathrm{X}$ is pleasant' or ' $\mathrm{X}$ is satisfying' or ' $\mathrm{X}$ is desired for its own sake under normal conditions.' G. E. Moore uses the "open question argument" to make this point. If someone were to say " $\mathrm{X}$ is pleasant," it always makes sense to ask: "But, after all, is $\mathrm{X}$ good?" Were ' $\mathrm{X}$ is pleasant' to exhaust the meaning of ' $\mathrm{X}$ is good,' that question would make no sense. For it would reduce to "But, after all, is X which is good, good?"

12. P. B. Rice, Ethical Empiricism and its Critics, 62 Philos. Rev. 355 (1953). 
Moore's open question argument relies upon two basic philosophical principles. The first of these says that to be clear about what goodness is is to be clear about the meaning of the word 'good' as it is used in evaluative discourse. This principle presupposes that a correct analysis of 'good' would be a transcription of everyday usage. Naturalistic analyses, on the other hand, are proposed not as reports of how people actually use the word 'good' evaluatively, but what they would mean by 'good' if they examined their ideas critically. Naturalists are reconstructionists. For them, part of the job of philosophy is to reconstruct language, i.e., to make linguistic proposals which are not mere transcriptions of everyday discourse. Moore is not a reconstructionist.

The second principle underlying Moore's open question argument says that to be clear about the meaning of the word 'good,' one must reflect carefully to discover the attribute or property named by the word. This principle presupposes that 'good' is a property word, like 'red.' The naturalists also assume that 'good' is a property word, but they deny that it names a nonnatural property. The non-cognitivists deny that 'good' is a property word at all in evaluative contexts. Those of the Oxford wing agree with Moore that philosophical analysis consists in faithful transcriptions of linguistic usage. But they modify Moore's first philosophical principle as follows: To be clear about what goodness is, or what truth is, or what necessity is (as against knowing that red, ripe, sweet strawberries are good, or that 'Electrons have a negative electric charge' is true, or that it is necessary that Monday follow Sunday), is to be clear about the ways in which the words 'good,' 'true,' 'necessary,' etc. are used in our language. This modification, which talks about 'use' and de-emphasizes meaning and regards as mistaken in principle Platonistic, phenomenological or mental-state theories of meaning is the result mainly of Ludwig Wittgenstein's influence. ${ }^{13}$

Moore and intuitionists in general hold that they have an immediate awareness of nonidentity in meaning between an ethical definiendum and its naturalistic definiens. In the contemporary atmosphere of empiricism and its concomitant mistrust of rational intuitions the intuitionist point against naturalistic definitions of ethical terms might have made less of an impression on naturalists, had not the non-cognitivists raised the same objection without appealing to rational insight into meaning relationships. That objection is that the definiens and definiendum of a naturalistic definition are not syn-

13. See his book, Philosophical Investigations (Macmillan, 1953). For an illuminating commentary on Wittgenstein's attack on Platonistic theories of meaning, see Paul Feyerabend, Wittgenstein's Philosophical Investigations, 64 PriLos. Rev. 449 (1955). 
onymous. How non-cognitivists argue this point will be explained in some detail below.

The naturalists have thus been forced to pay close attention to the problem of showing that the two sides of a naturalistic definition are alike normative. If the definiendum, e.g., ' $\mathrm{X}$ is good,' is normative and the definiens, ' $\mathrm{X}$ is pleasant' or ' $\mathrm{X}$ is desired under normal conditions,' is empirical; and if the empirical is ipso facto non-normative, then the anti-naturalists are right: no naturalistic definition can be correct. Some naturalists have tried to meet the objection by expanding the definiens of ' $\mathrm{X}$ is intrinsically good' into a complex predicate, e.g., ' $\mathrm{X}$ is desired for its own sake under normal conditions.' The explicit reference to the desired ('for its own sake') has seemed to them to carry the normative force of the definiendum, and the reference to the desired under cognitively trustworthy conditions ('under normal conditions') has seemed to distinguish rationally defensible valuations from those which are capricious and to strengthen further the normative force of the defining phrase. The underlying presumption is that to desire something is to find it prima facie worth desiring. And to desire something for its own sake under cognitively trustworthy conditions is to find it de facto worth desiring. Such a definition, in short, is proposed because it is presumed to provide a criterion for rationally justifying evaluations and because it presumably injects into its definiens a normative force equal to that of the definiendum.

The intuitionists are not mollified by these emendations. They concede that pleasantness or being desired under normal conditions are "good-making characteristics," but they are not identical with good-ness. Goodness, obligatoriness, right, and the like are sui generis. They are properties objectively qualifying things or situations. But they are not sensorily discriminable (empirical) properties. If we call the empirical properties of the naturalists 'natural properties,' then goodness, obligatoriness, and rightness are nonnatural properties.

The theory of nonnatural properties accomplishes the following things. It provides irreducible normative properties as the referents of irreducibly normative ethical words. It preserves the truth-values of normative ethical judgments without reducing them to the empirical. It provides a connection between good-making and ought-implying natural characteristics on the one hand and nonnatural normative characteristics on the other hand without identifying the former with the latter. According to G. E. Moore, to say a characteristic is ought-implying, means "[it is] such that, when a state of affairs possesses it, then the fact that an action, which an agent would do, would produce that state of affairs is favorably relevant (though only in a 
very weak degree) to the hypothesis that the agent ought to do that action." 14 For example, conduciveness to the alleviation of suffering is ought-implying. The intuitionists concede that some natural properties are intimately connected with moral values. But the intuitionists also insist that these natural properties are not identical with moral values.

The nonnatural normative properties and their connections with goodmaking and ought-implying characteristics are said to be known by an $a$ priori rational intuition. The connection is synthetic a priori. ${ }^{15}$

The intuitionist position in ethical theory may be summed up as follows: (1) Ethical sentences are judgments, being either true or false. (2) Their truth-value is known independently of any experimentation or observation characteristic of the natural sciences; they are known a priori, non-inferentially by an immediate rational intuition (they are synthetic a priori). (3) Ethical words, e.g., 'good,' 'right,' name nonnatural objective normative properties; they are not definable by words referring to empirical properties.

If ethical intuitionism is true, jurisprudence is committed to rationalism. The consequence for ethical jurisprudence, then, is this: the questions of ethical jurisprudence have true or false philosophical answers because intuitionism entails the legitimacy of normative ethics. The answers will be synthetic a priori judgments.

Intuitionism has consequences also for analytical jurisprudence. Let us recall that analytical jurisprudence is partly concerned with definitions of legal terms. and with identifying legal premises. Assuming that legal terms, like ethical terms, are normative, intuitionism entails the wholesale removal from analytical jurisprudence of all attempts to define legal terms empirically. To account for the normativeness of legal terms, an intuitionistic analytical jurisprudence would either have to posit nonnatural legal properties analogous to nonnatural ethical properties, or it would have to define legal terms by ethical or otherwise normative terms. Basic legal premises, because they contain empirically irreducible extralogical vocabulary, could not be regarded as empirically factual statements. They would have to be construed as synthetic a priori judgments.

14. The Philosophy op G. E. Moore, 603-604, 556, 596 ff. (P. A. Schilpp ed., Northwestern, 1942).

15. The synthetic a priori is a technical notion in rationalistic epistemology. Whether there are synthetic a priori judgments is a moot question in philosophy. Those who accept synthetic a priori judgments say that they are nontautological yet necessary judgments whose truth or falsehood is known by an act of reason independently of experience. In effect, they are saying that there can be a necessary though factual connection between at least two factors, the necessity of which connection is seen in a pure rational insight. That the same surface cannot at the same time be blue and yellow all over is often given as an example of a synthetic a priori truth (a synthetic a priori judgment that is true). 
Let us illustrate these points by applying intuitionism to Kelsen's pure theory of law. One may suppose that the basic premise, or basic norm (in Kelsen's terminology), of English law runs something like this: "What the King in Parliament has promulgated or authorized or permitted to be promulgated as law ought to be observed." 16 This is a normative sentence, irreducible, by Kelsen's showing and by intuitionist standards, to an empirical or otherwise descriptive sentence. It is not a simple report of how the English make laws. Nor is it a report of what laws the English observe. There are plenty of lawbreakers in England. Now for Kelsen the basic norm is not cognitive. At any rate, he leaves that question open. As an analytical jurist the validity which he assigns to the basic norm is that of a "hypothesis" or unifying principle, which is not true or false but either useful or useless. It is useful to the extent that the subsidiary norms of the system can be hierarchically derived from it.

The basic norm contains an "ought." In our example, what the King decrees "ought to be obeyed." This occurrence of 'ought' is extralegal. For, in a Kelsenite framework, the basic norm's 'ought' cannot be interpreted to mean 'legally ought,' because the legality of a law is relative to its validity in a legal hierarchy. We need the basic norm before we can tell which are the laws of the legal system. In other words, 'legally ought' (in a Kelsenite framework) means 'that which is derivable from a norm in a legal hierarchy.' But since the basic norm is, by hypothesis, (legally) underived, its 'ought' cannot mean 'legally ought.' Unless there is an extralegal 'ought,' the normativeness of the basic norm remains unexplained.

Intuitionism has an answer to this problem. The basic norm must be synthetic a priori, for it connects a normative property (an extralegal ought) with a natural characteristic (being decreed as law by the King in Parliament). Being synthetic a priori, it must be true or false. Therefore, it cannot be a stipulation functioning as a morally neutral unifying "hypothesis." A stipulation may be either an empirical prediction (e.g., I shall, as a matter of fact, use the word $\mathrm{X}$ to mean $\mathrm{Y}$ ) or a resolution (e.g., let us use $\mathrm{X}$ to mean $Y$ ). A prediction is factual, hence not normative. A resolution or command is not true or false, hence not normatively true or false.

As to codifying law, the intuitionism of an analytical jurist (logically) leaves him free to choose between a monistic codification, such as Kelsen's and Austin's, or a pluralistic one, such as Hohfeld's. ${ }^{17}$ This, as I suggested above, is a matter to be decided relative to one's view as to the nature of the legal subject matter.

16. See Stone, op. cit. supra, note 1 at 94 .

17. For a critical exposition of Hohfeld see Stone op. cit. supra, note 1, c. 5 . 


\section{III}

Next on our list are the non-cognitivists. This group consists of the Logical Positivists, C. L. Stevenson, and the Oxford philosophers of ordinary language ('Oxford philosophers' for short).

The Logical Positivists are typically represented by A. J. Ayer in his Language, Truth and Logic. Ayer agrees with G. E. Moore and the intuitionists at large that naturalistic definitions of ethical terms are faulty for the reason advanced by the intuitionists: the normative force of the definiendum has no counterpart in the definiens. But Ayer's explanation of this is very different from the intuitionists'. We recall that for intuitionism the normative meaning of normative words derives from their naming some nonnatural normative property. Ayer's explanation is that normative words are "pseudoconcepts." They do not name any qualities or relations, either empirical or logical. And, since for Ayer genuine concepts are either empirical or logical, ethical concepts are not genuine concepts at all. Normatively functioning concepts and sentences are "purely "emotive." For Ayer, there are two dimensions of meaning, the cognitive and the emotive. The empirically verifiable and the logically certifiable exhaust the cognitive. All else is emotive. To say that an expression is emotive means that it either evinces or arouses an emotion. To evince an emotion is distinct from stating that one has the emotion. A blush, a yawn, an interjection, a stimulus, "whoa" to move a horse, a command to a man, "Stand up!"-all are lumped together into the emotive (non-cognitive) category. They assert nothing, not even about feelings. They merely evince feeling.

Words like 'good,' 'bad,' 'ought,' 'lovely,' 'worthy,' are, from this view, like blushes and yawns. "If I say to someone, 'you acted wrongly in stealing that money,' I am not stating anything more than if I had simply said, 'You stole that money.' In adding that this action is wrong I am not making any further statement about it. . . . If now I generalize my previous statement and say, 'stealing money is wrong,' I produce a sentence which has no factual meaning-that is, expresses no proposition which can be either true or false. It is as if I had written 'Stealing money! !--where the shape and thickness of the exclamation marks show, by a suitable convention, that a special sort of moral disapproval is the feeling which is being expressed." 18

Ayer is careful to point out that it is only the normative use of ' $\mathrm{X}$ is

18. A. J. Ayer, Lanouage, Truth and Loatc 107 (2nd ed., 1946). 
good,' ' $\mathrm{X}$ is wrong' which he characterizes as emotive. The same form of words could be used descriptively, as when I say, "In cannibal culture, eating human flesh is right," meaning that cannibal cultures as a matter of fact approve of eating human flesh. This is a sociological statement. It is a non-incitive, descriptive statement. In usual ethical discourse, however, ethical words are intended not descriptively but normatively. If we are to give a faithful analysis of actual ethical usage, we must account for the peculiarly incitive force of ethical words, and the emotive theory does this without invoking logically inadmissible nonnatural properties or without trying to define normative words in terms of descriptive words. This, too, is logically inadmissible because the normative and the descriptive are exclusive (and, in Ayer's view, also exhaustive). A normative definiendum can never be defined by non-normative definientia. The logical error here is analogous to the error of deriving (inductively or deductively) a normative conclusion from premises all of which are non-normative.

An ethical theory such as Ayer's implies "that ethical philosophy consists simply in saying that ethical concepts are pseudo-concepts. . . . There cannot be such a thing as ethical science, if by ethical science one means the elaboration of a 'true' system of morals. For we have seen that, as ethical judgments are mere expressions of feeling, there can be no way of determining the validity of any ethical system, and, indeed, no sense in asking whether any such system is true. All that one may legitimately enquire in this connection is, what are the moral habits of a given person or group of people, and what causes them to have precisely those habits and feeling? And this inquiry falls wholly within the scope of the existing social sciences." 19

An analytical jurist who accepts a theory such as Ayer's has first to decide whether legal concepts are straightforward empirical ones or whether they are something else. If he can demonstrate (and I do not think he can) that legal terms are just empirical terms, he will show they are defined in terms of psychology, sociology, economics, political science, culturology or any other relevant empirical discipline. He will stop calling legal terms 'normative.'

Legal premises, on this view, will be empirical statements, subject to the rules of formal logic. A jurist who accepts a logical positivistic ethical theory is likely (though not logically compelled) ${ }^{20}$ to accept the epistemological orientation positivists share with certain other philosophers. Part of this orientation is a theory of what philosophical analysis is. It is a linear

19. Id. at 112 .

20. B. Russell, for instance, holds an ethical theory like Ayer's. Yet Russell repudiates many of the epistemological theses of logical positivism. 
affair; its model is Whitehead and Russell's Principia Mathematica. First comes the discovery of an analytically adequate base. This means an analytically adequate set of primitive concepts and primitive sentences. An analytically adequate set of primitive sentences (axioms) is complete, i.e., it is sufficient for deriving within the system and by the rules of derivation or transformation all the theorems in the system. And an analytically adequate set of primitive concepts is one which is sufficient for constructing a complete axiom-set. In Quine's Mathematical Logic, ${ }^{21}$ for example, which is in the Russell-Whitehead tradition, there are three primitive concepts: 'neithernor,' 'each and every' (universal quantifier), and ' $\mathrm{X}$ is a member of the class a.' All the axioms of the system can be written in terms of these concepts. The (infinite) axiom set of the system is complete for classical mathematics.

For a (logical) positivistic analytical jurist, who proposes, for some reason or other, that legal concepts are non-normative, an analytically adequate set of legal primitives would be a set of empirically interpretable ${ }^{22}$ legal concepts sufficient for formulating a complete set of axioms for a legal code or parts of it.

On the other hand, if a (logical) positivistic analytical jurist decides that legal concepts are, after all, normative, the consequence for analytical jurisprudence will be to treat all legal concepts as emotive ejaculations. From the assumption that these ejaculations are neither true nor false, we would have to conclude that we cannot speak of a logical codification of the law. Ejaculations are not subject to logical manipulation, and at least the general precepts of the law would be, in this view, mere ejaculations. There is, however, a way out of this. It calls for an extension of formal logic. Logic, as conceived by logical positivists, deals with logical relations among statements. Statements are linguistic expressions which are true or false. Within this narrow conception of logic, linguistic expressions which are not statements cannot be handled logically. Although logical positivists have been exclusively preaccupied with the logic of statements, nothing in their general orientation forbids an enlarged logic. This would be a logic in which normatives as well as indicatives could be handled in accordance with certain well defined rules.

Here, for example, is a standard valid argument all sentential components of which are indicative statements:

21. I omit here certain refinements of statement which would be necessary in a precise description of the system.

22. As legal primitives, the concepts would be undefined within the legal code. But, since we are working here on the assumption that legal concepts are empirical, there should be, if not explicit definitions, at least operational specifications of how the legal primitives are to be given empirical interpretation. 
All those boxes will go to the storeroom.

This is one of the boxes.

Therefore, this will go to the storeroom.

There are well-known standard rules for determining the validity of this inference. Suppose now we argue as follows:

You should take all the boxes to the storeroom.

This is one of the boxes.

Therefore, you should take it to the storeroom.

The logic of logical positivists has no rules for handling this. One of the premises and the conclusion are non-indicative (normative). Yet this is typical of the sort of argument that occurs in the language of morals and the law. From a legal norm together with a relevant factual premise we draw a conclusion of law (normative).

Such inferences can be assimilated into deductive (and inductive) logic provided that to the rules of the existing logic of indicatives are added suitable rules for manipulating non-indicatives as well. Logical positivists can go about constructing such a logic by introducing syntactical rules ${ }^{23}$ for drawing purely syntactical distinctions between indicatives and imperatives (normatives, in general). Ayer's characterization of normative utterances as emotive ejaculations is pragmatic. In pragmatics, his theory does not discriminate (and this is a mistake) functionally between an ethical utterance and an involuntary ejaculation.24 But Ayer's position does admit of drawing a syntactical distinction between the imperative 'You should take the boxes to the storeroom' and the indicative 'All the boxes are going to the storeroom,' as some philosophers have done.

Thus, Ayer's position in ethical theory can be made to allow codification in analytical jurisprudence. The normative elements in the code, when interpreted, would have only "emotive" meaning and would not be true or false. But they would be, syntactically, subject to rigid logical canons.

As to ethical jurisprudence, whether legal concepts are treated as purely descriptive or as purely emotive will make no difference. The ethical theory of logical positivism implies that normative ethics cannot be a theoretical discipline. Therefore, no question can arise as to the relation between normative ethics and ethical jurisprudence. What are the ideals to which

23. A syntactical rule is prescriptive about typographical shapes. For example, "the word 'ought' is to be taken as an abbreviation for 'it is not the case that may not'" and " 'p' and ' $q$ ' are to be taken as atomic formulae" are syntactical rules. They make no mention of how the typographical shapes are to be interpreted in terms of extralinguistic reference.

24. For a thoughtful criticism see John Dewey, Theory of Valuation, 2 International Encyclopedia of Unified Science, No. 4 (Chicago, 1939). 
we ought to make the legal order conform? If taken as a normative question, it is really a pseudo-question. Grammatically it is a request for information. Semiotically, it is an inciter, a stimulus which normally would evoke responses including normative utterances. But, according to the theory, these are on a par with involuntary ejaculations. There is no question here of a rational debate as to the merits of one ethical injunction over another. If "We find that ethical philosophy consists simply in saying that ethical concepts are pseudo-concepts," 25 then we must conclude that ethical jurisprudence consists simply in saying that the questions it poses are pseudo-questions.

To sum up, the student of jurisprudence who adopts the ethical theory of logical positivism and who also decides that legal concepts are normative must regard ethical jurisprudence as a non-theoretical discipline. The answers to its questions are non-objective. He will do sociological jurisprudence, and he may also do analytical jurisprudence, but only after he has worked up a syntactical system of logic suitable for logically manipulating syntactically normative forms.

Charles L. Stevenson's Ethics and Language ${ }^{26}$ defends a view akin to but not identical with the ethical theory of logical positivism. Ayer denies that there are irreducibly ethical disagreements. All ethical disputes are carried on within a framework of moral presuppositions which themselves are beyond dispute. "What we do not and cannot argue about is the validity of these moral principles. We merely praise or condemn them in the light of our own feelings." 27 Every argument on a question of value is reduced to an argument about a question of logic or about an empirical matter of fact.

Ayer never says what criterion distinguishes "ethical" or "moral" feeling from feelings of other sorts. Stevenson, on the other hand, has an elaborate theory on this subject. He locates the distinctively ethical in attitudes which are contrasted to beliefs. Ethical disagreements are genuine and irreducible. They are disagreements in attitude. In agreement with the logical positivists, Stevenson regards questions of belief to be questions of logic or of empirical fact. Attitudes, on the other hand, have to do with purposes, desires, interests, preferences and the like. When two people have an ethical disagreement, in Stevenson's view this means simply an opposition of attitudes. For in ethics we deal with agreements or disagreements in attitudes.

A value judgment ' $\mathrm{X}$ is good' means (roughly, but essentially), ' $\mathrm{I}$ approve of $\mathrm{X}$. Do so as well.' This is a compound statement. One component is an indicative sentence giving factual information (capable of being true or

25. Ayer, op. cit. supra, note 18 at 112 .

26. Yale University Press, 1944.

27. At 111-112. 
false). The second component is an imperative. Now we can see why Stevenson does not simpliciter deny the three fundamental theses of a naturalistic ethics. The definiens is not simply a factual statement. Neither is it simply a command or imperative. A value judgment is a complex thing. In addition, Stevenson uses 'meaning' as follows: the meaning of a sign is its capacity to arouse certain kinds of psychological responses. If the responses are cognitions, the sign is said to have descriptive meaning. When the responses are attitudes, the sign is said to have emotive meaning. The word 'good' has a complex meaning. It is partly emotive, partly cognitive. The distinctively normative or ethical meaning of good, however, is its emotive meaning: ". . . an ethical judgment can be true or false, but . . . its descriptive truth may be insufficient to support its emotional repercussions." 28

Are all ethical disagreements (disagreements in attitude) rooted in disagreements in belief? Stevenson thinks that they are not. Nevertheless, the changing of one's beliefs is very often the determining of changes in one's attitudes. So, there is a strong connection between questions of belief and questions of attitude. But, factual or otherwise, rational appeals have no privileged position. For the distinction between valid and invalid, cogent and incogent applies only to inductive or deductive proofs. Ethical reasoning, in which an ethical conclusion is supported by factual premises, is neither inductive nor deductive. (This is so because no valid deductive and no cogent inductive argument can exist if its conclusion is normative while its premises are not.) Inferences from factual reasons to ethical conclusions, rather than being either valid or invalid, are either successfully persuasive or unsuccessfully persuasive. Being a civilized man, Stevenson himself prefers rational methods to nonrational ones. But he maintains that we have no reason for saying that every disagreement in attitude is grounded in a disagreement in belief. Therefore, we cannot say that where an ethical disagreement exists, there is always a way of dissolving it by appeal to factual considerations.

In spite of similarities, there are differences between Stevenson and the ethical theory of the logical positivists. The important similarity is that for both theories the normative is the emotive. But for Stevenson, the same sign functions in part descriptively and in part emotively, while for the logical positivists, if a sign is functioning emotively, it cannot at the same time and for the same interpreter function descriptively. A second important difference is that the logical positivists, as exemplified by Ayer, leave unspecified the differentia of "moral" or "ethical" feeling. Stevenson devotes close analysis

28. Ethics and Language 267 (1944). 
to this in terms of an attitude-belief distinction. Thirdly, the positivists regard the notion of ethical reasoning as meaningless. Stevenson regards it not as meaningless, but as being on a par with nonrational persuasion. It has already been stated that in the languages of ethics and law inferences are drawn from premises (some of which are normative) to conclusions which are normative. It has been suggested that a suitably enlarged formal logic would enable logical positivists to recognize such inferences and appraise their logical cogency as a matter of syntax. The same is true of Stevenson. But there is another class of ethical inferences. In these, ethical conclusions are supported by nonethical premises. For instance: "You shouldn't come in with muddy shoes because mommy just scrubbed the floors," would be a good argument if addressed to a child. We can see that it is a good argument for a child if we contrast it with ". . . because we bought the linoleum from Sears." Philosophers who recognize arguments of this type admit that they are neither deductive nor inductive. They call such arguments ethical inferences. Now the logical positivists would rule out as meaningless such ethical inferences, because for them an inference is either inductive or deductive. Stevenson does not go this far. He agrees with the logical positivists that this type of inference is not subject to the valid-invalid distinction. But this fact does not make meaningless the very concept of this sort of inference. Instead of trying to include these patterns of inference among the formal deductive or inductive patterns, he classifies them as persuasive patterns. Factual reasons are often powerfully persuasive. They are successful in redirecting attitudes. Roughly, in a logical argument, the end result is a cognition. In a persuasive argument the end result is an attitude.

On the whole, the consequences of Stevenson's ethical theory for jurisprudence are the same as those of logical positivism. For analytical jurisprudence, the consequences are these: any adequate analysis of normative legal concepts must take into account their emotive meaning. There are no natural or nonnatural normative properties. The normative function of normative legal terms and of normative legal principles is determined by their capacity to arouse attitudes in interpreters. So far in the analysis, there is no reason why the syntax of the language of the law could not be formalized, or why we should not codify as much of the legal system as lends itself to codification within a formal logic sufficiently enriched to handle sentences of the imperative family.

Stevenson's theory rules out normative ethics as a theoretical discipline. The answers to the ethical jurisprudential questions are not contained in some objective ethical norms, but rest in some persuasive methods whereby it is hoped agreement in attitudes can be reached. 
Let us now proceed to the Oxford philosophers. I have included the Oxford ordinary language philosophers among the non-cognitivists because they deny the central theses of naturalism and intuitionism. In this they agree with Stevenson and the logical positivists. Oxford philosophy represents a revolutionary conception of philosophical activity. Its influence is growing daily, and its conception of how we should philosophize has far-reaching consequences for the methodology of analytical and ethical jurisprudence. These are two important reasons for becoming familiar with their views. ${ }^{29}$

Philosophers of the Oxford persuasion who have written important books or articles bearing upon ethical theory include S. Toulmin, ${ }^{30} \mathrm{R}$. M. Hare, ${ }^{31}$ H. P. Nowell-Smith, ${ }^{32}$ J. O. Urmson, Stuart Hampshire, J. L. Austin, and H. L. A. Hart. Of these men, Hart is the only specialist in jurisprudence. $\mathrm{He}$ is currently Professor of Jurisprudence at Oxford.

Hart is exclusively concerned with the problems of analytical jurisprudence. In the immediately following paragraphs, I shall report what it is that Hart is trying to do in the field of analytical jurisprudence. I shall then consider the views of Toulmin and Hare as they relate to the problems of ethical jurisprudence.

I shall refer to two of Hart's papers. The first paper, "The Ascription of Responsibility and Rights," appeared in 1951.33 The second paper is Hart's inaugural address at Oxford, delivered in May, 1953, on the occasion of his assuming the chair of Jurisprudence. ${ }^{34}$ I shall use the first paper as a commentary on the second.

The task of analytical jurisprudence, according to Hart, is to dispel the perplexities which confront us when we realize that we know perfectly well how to operate with legal concepts and yet we do not understand them. This sort of perplexity cannot be resolved by consulting dictionaries. Nor can they be resolved by citing examples of rights, contracts, corporations and the like. A competent student of the law knows the dictionary definitions and can recognize examples of rights and the like. Yet he is puzzled, and he is puzzled because legal words, compared with ordinary words, are in different ways anomalous. ${ }^{35}$

29. For more examples and a somewhat general characterization of the new Oxford movement, see Gilbert Ryle, Ordinary Language, 62 Prinos. Rev. 167, and Morris Weitz, Oxford Philosophy, id. at 187 (1953). These papers will suggest further reading for those whose curiosity may be aroused.

30. An Examination of the Place of Reason in Ethics (Cambridge, 1950).

31. The Language of Morals (Oxford, 1952).

32. Ethics (Pelican [A 298], 1954).

33. Essays in Logic and Language 145 (A. Flew ed., Philosophical Library, 1951).

34. Definition and Theory in Jurisprudence, 70 LAW QUARTERLY Review 37 (1954).

35. Op. cit. supra, note 34 . 
One anomaly is illustrated by the words 'legal right.' Hohfeld has distinguished four species under the general category of legal rights: right, privilege, power, and immunity. Is the word 'right' applied to these four very different species a mere homonym? We have a pre-analytic conviction that the word is not a mere homonym, and that there is a principle behind the application. Yet we are at a loss to say just what that principle is. Another anomaly of some legal words is that unlike words such as 'chair' or 'horse' they have no obvious counterparts in the world. And so the traditional theories propose certain unobvious counterparts. The legal Platonists propose disembodied universals. The American Realists aver that the word 'right' refers to our predictions as to the probable behavior of courts or officials. The Scandinavian jurists say that a right is a fictitious entity.

These attempts, according to Hart, are misleading. They formulate the problems in the form of questions such as these: What is law? What is a state? What is a right? What is possession? But these are requests for definitions. These requests, in turn, presuppose that legal concepts are capable of being defined by specifying necessary and sufficient conditions for their application. Formulating the problem in this manner, Hart thinks, has led at certain points to a divorce between jurisprudence and the study of the law at work. It has created the impression that certain fundamental legal concepts cannot be elucidated "without entering a forbidding jungle of philosophical argument." The remedy Hart suggests is to take a fresh look at the ways in which these legal concepts do their work in the language of the law as it exists. The philosopher's job is to elucidate these specialized functions. This is an application of the methodological principle espoused by Oxford philosophers: to be clear about what law, contract, etc. are is to be clear about the ways in which the words 'law,' 'contract,' etc. are used in legal language.

The basic reason why it is futile to try to define legal terms by reference to necessary and sufficient conditions for their application is that in the language of the law legal terms perform functions which are radically unlike the way words or phrases such as 'chair' or 'heavier than' do their work. This latter class of words is used to describe facts or name publicly observable things and properties. We are in no doubt as to the general class to which chairs belong. It is, therefore, possible, if we so choose, to look for the specific differences between chairs, tables, stools and the like. It is, in short, possible to give a definition of 'chair' in terms of a genus and a differentia which are necessary and sufficient for the application of the word. A phrase like 'heavier than' can also be defined in terms of necessary and sufficient conditions. In this case, however, the necessary and sufficient formal conditions are not given 
per genus et differentiam but rather in terms of asymmetry, transitivity, and identity supplemented by operational (material) conditions involving performances with scales or other apparatus.

Take now the legal use of the word 'contract.' What is a contract? If we put the question this way, we may be misled either to say that a contract is a fictitious entity or a Platonic universal or a word which refers to complex facts. But these theories fail to elucidate the actual work that the word 'contract' does in legal discourse. This is the trouble with erecting a legal theory on the basis of a definition. The definition fails to explain the actual function of the word in law; hence the theory based on the definition fails to be a theory of the law as it exists. This is what makes such theories inadequate.

The first step in the right direction is to examine the use of legal words in sentential contexts. We should elucidate not 'contract,' but 'A has a contract with B.' If we omit to look closely into the actual workings of the law, we may be tempted to think that 'A has a contract with $B$ ' states a fact; that its logical status is no different from 'A has eyes the color of B's.' This would be a mistake. When uttered by a judge in a law court, 'A has a contract with B' is neither a factual statement nor a device for evincing or kindling feelings or expressing or arousing attitudes. It is a conclusion of law.

The characteristic difference between typically legal utterances and typically factual utterances is that the former are defeasible. An examination of the defeasible character of legal claims will show that legal words cannot be defined in terms of necessary and sufficient conditions.

Every lawyer knows that in England and in the United States the law insists on certain conditions necessary for a prima facie contract. There must be at least two parties, an offer, an acceptance, a consideration, and in certain specified types of situations a written document. But the mere existence of these conditions is not sufficient to establish a contract. There are certain defenses, the presence of any one of which would either nullify or weaken a claim. In short, a prima facie claim 'A has a contract with $B$ ' is defeasible.

The same point may be illustrated by the following example. This illustration is illuminating in that it shows an essential similarity between a legal claim in court and a "non-legal" claim out of court. Someone drops his wallet. I pick it up, catch up with him and say, "This is your wallet." Now imagine that the police drive up and arrest the man for having stolen the wallet. Given this new information, I would no longer say that the wallet is his. This shows that 'This is your wallet' in this context is not equivalent to 'This was in your pocket and you dropped it,' nor to any other descriptive statement. Any descriptive statement which truly describes the facts before the coming of the police remains true. But I now withhold 'This is your 
wallet.' In the present context, 'This is your wallet' ascribes a right, and any such ascription is defeasible. Moreover, my unofficial utterance is, nevertheless, like the utterance of a judge in court. It is a conclusion of law.

In a different context, 'This is yours' can function primarily and, indeed, purely descriptively, as for instance when I say 'Yes' to a patient who is just coming out of anesthesia and who asks me if the hand he sees on his bedsheet is his. It is the context that determines the function. In legal contexts, sentences used to ascribe responsibilities and sentences used to make claims or confer rights are alike in that they are all defeasible.

Let us return to the example from contracts to see how Hart supports his thesis that legal concepts are not susceptible of definition by necessary and sufficient conditions. In the first place, the distinction between the positive (i.e., necessary) conditions for the prima facie existence of a contract and the defenses is legal and not formal. Call the positive conditions 'P-conditions' and the defenses 'D-conditions.' We can always make a conjunction of the P-conditions with the negated D-conditions. Thus we can say a contract exists if, and only if, $\mathrm{P}_{1} \mathrm{P}_{2} \mathrm{P}_{3} \overline{\mathrm{D}}_{1} \overline{\mathrm{D}}_{2} \overline{\mathrm{D}}_{2} \ldots \overline{\mathrm{D}}_{\mathrm{n}}$. Formally, there is no difference between, say, $P_{1}$ and $\bar{D}_{1}$. If either $P_{1}$ fails or $\bar{D}_{1}$ fails, the contract is either voidable or weakened. But, as the law actually works, there is a legal difference between the $\mathrm{P}$ - and the $\mathrm{D}$-conditions. The P-conditions are determined by legal precedent to be necessary for the prima facie existence of a contract. A lawyer does not file action in contract if one of the Pconditions is clearly absent. The D-conditions usually come up later when the case is before the judge and jury. Legally, then, the list of P-conditions is complete. This is not to say, of course, that decisions as to the existence or absence of any of the P-conditions are mechanical. Words like 'offer' and 'acceptance' are vague. Their application sometimes calls for legal decision. But this vagueness is also shared by the $\mathrm{D}$-conditions. The significant respect in which the $\mathrm{P}$ - and $\mathrm{D}$-conditions differ is that the D-conditions are not spelled out in exact detail. The conjunction $P_{1} P_{2} P_{3} \bar{D}_{1} \bar{D}_{2} \bar{D}_{3}$ $\ldots \overline{\mathrm{D}}_{\mathrm{n}}$ is open-ended. In a book on contracts we may find what looks like an exhaustive list of defenses. But the language in which they are stated does not supply the judge with mechanical criteria of application. For example, one defense is undue influence. This is an umbrella term which covers a multiplicity of particular facts which may have nothing in common except that they come under the same rule. It will not do to say that the term 'undue influence' is meant to rule out some positive condition such as the absence of a state of mind characterized as 'full and free consent.' The judge decides only on the publicly supportable evidence. His job is not to take the evidence of economic pressure or social pressure as evidence for the existence of a 
common state of mind induced by these two dissimilar types of coercion. The legal cash value of undue influence is just the proved fact of some particular pressure, social, economic or otherwise: ". . . the defense, e.g., that B entered into a contract with $A$ as a result of the undue influence exerted upon him by $A$, is not evidence of the absence of a factor called 'true consent,' but one of the multiple criteria for the use of the phrase 'no true consent." 36 To say, then, that $P_{1} P_{2} P_{3} \bar{D}_{1} \bar{D}_{2} \bar{D}_{3}$ is open-ended is to call attention to this fact, namely, that no exhaustive and detailed list of defenses can be supplied antecedently to any particular occasion of a judge's decision. This is different from saying that umbrella terms are vague or ambiguous. When new defenses are legally made to fall under the rule of undue influence, this in no way affects the vagueness or ambiguity of the phrase 'undue influence.'

This peculiarity of the open-endedness of the defeating conditions rules out the possibility of defining a word such as 'contract' as used in the law by reference to necessary and sufficient conditions. Hence any theory which rides upon the back of such definitions is bound to misrepresent the practice and procedure of the law.

The proper method of elucidating such legal words as 'contract,' 'right,' and the like is to ask not: What is a contract? What is a right? The proper way is first to elicit the conditions under which decisions such as ' $A$ has a contract with B' or 'A has a right with respect to B' are true and, second, to describe the peculiar job that such utterances perform in legal discourse.

As a model of this sort of analysis, Hart gives an elucidation or analysis of 'a legal right.'

(1) A statement of the form ' $\mathrm{X}$ has a legal right' is true if the following conditions are satisfied:

(a) There is in existence a legal system [with all that this implies by way of general obedience, the operation of the sanctions of the system and the general likelihood that this will continue].

(b) Under a rule or rules of the system some other person $\mathrm{Y}$ is, in the events which have happened, obliged to do or abstain from some action.

(c) This obligation is made by law dependent on the choice either of $\mathrm{X}$ or some other person authorized to act on his behalf so that either $\mathrm{Y}$ is bound to do or abstain from some action only if $\mathrm{X}$ (or some authorized person) so chooses or alternatively only until $\mathbf{X}$ (or such person) chooses otherwise.

(2) A statement of the form ' $\mathrm{X}$ has a right' is used to draw a conclusion of law in a particular case which falls under such rules. ${ }^{37}$

36. Op. cit. supra, note 33.

37. Op. cit. supra, note 34 at 49 . The bracketed material is interpolated from id. at 42 . 
There are several points worth noticing in this elucidation. In the first place, the conditions (a), (b), (c) are necessary but not also sufficient for defining 'a legal right.' Y's obligation mentioned in condition (b) depends upon the absence of D-conditions. Y's lawyer can argue that although all the circumstances on which X's claim could succeed are present, yet in the particular case the claim should not succeed because other circumstances are present which brings the case under some recognized head of exceptions. In short, X's claim is defeasible. Thus, Hart's elucidation of 'a legal right' is not in terms of necessary and sufficient conditions.

In the second place, Hart says that a statement of the form ' $\mathrm{X}$ has a right' is used to draw a conclusion of law. This merits some attention because it is based upon the proposition that utterances in legal discourse which make claims (This is mine), yield claims (Yes, this is yours), or give decisions (A owes $B$ ten dollars) are performing a job altogether different from statements of fact or phrases which we use to influence or evince emotions. In the language of lawyers 'This is mine' or ' $\mathrm{X}$ has a right' are 'operative words.' By the utterance of such sentences, especially in the present tense, we often do not describe but actually perform or affect a transaction. With them "we claim property rights, confer or transfer such rights when they are claimed, recognize such rights or ascribe such rights whether claimed or not." 38

Let me sum up by reviewing the four characteristics which Hart says constitute the distinctive features of legal words like 'right,' 'contract,' or 'duty.' (1) An utterance ' $X$ has a right' tacitly assumes 'a special and very complicated setting, namely, the existence of a legal system. . . . But though this complex situation is assumed in the use of these statements of rights or duties they do not state that it exists." 39 Nor do they make predictions that the rules will be enforced. "No doubt, when someone has a legal right a corresponding prediction will normally be justified, but this should not lead us to identify two quite different forms of statement." 40 (2) 'X has a right' not only presupposes the existence of a legal system but it also has a special connection with a particular rule of the system. This can be seen when we ask: 'Why does $\mathrm{X}$ have a right?' But again, ' $\mathrm{X}$ has a right' does not state the relevant rule to which we appeal to answer 'Why does $\mathrm{X}$ have a right?' One who says ' $\mathrm{X}$ has a right' has drawn a conclusion from the relevant and unstated rule and from the relevant and unstated facts of the case. ' $\mathrm{X}$ has a right' is "the tail-end of a simple legal calculation: it records a result and may be well called a conclusion of law. It is not there-

38. Op. cit. supra, note 33.

39. Hart, op. cit. supra, note 34 at 42.

40. Ibid. 
fore used to predict the future as the American Realists say; it refers to the present . . . but unlike ordinary statements does not do this by describing present or continuing facts." 41 (3) The assertion ' $X$ has a right' stated by a judge in deciding the case has a different meaning than the like statement uttered out of court. The judge's utterance is official, authoritative, and, let us assume, final. The utterance out of court is none of these. Still, in spite of these differences, the statements are alike; they are both conclusions of law. Be they official or unofficial, they are decisions made by appealing to relevant rules and relevant facts, but they neither mention nor describe either the rules or the facts. They thus perform a special job, which is different from the job done by descriptive or emotive utterances. (4) "In any system, legal or not, rules may . . . attach identical consequences to any one of a set of very different facts." 42 Take the game of baseball: you are "out" if you either struck out, popped out, or are tagged out. No two of these ways of being "out" need have anything in common except that they come under the same rule which attaches identical consequences to them, namely, that you stop playing until your next turn comes up.

What Hart is doing here is typical of the Oxford analysts. Philosophical analysis aims to elucidate language, and the way to elucidate is to see, in typical contexts, how whatever you are trying to elucidate is typically employed. Thus, the evaluative use of 'good' is to prescribe or commend. Any analysis which overlooks this linguistic fact or proposes a use for 'good' not in conformity with its standard use is ipso facto wrong. The task of the philosopher is not "to devise or sanction linguistic usages-especially when this activity involves misrepresenting our existing concepts. It is more his business to analyze the sense of [the concept in question] (and the criteria [for its application]), which are already implicit in our ethical discussions, and whose existence cannot be explained away. . ." 43

The Oxford analysts deny that ethical words are-simply descriptive or simply prescriptive. They maintain, however, that the prescriptive meaning of these words is primary. R. M. Hare, for instance, argues that the prescriptive sense remains constant for every class of objects whereas the descriptive sense varies with each class; that the descriptive sense can be made to change by using the prescriptive sense, but not vice versa; and that it is possible to teach the typically prescriptive sense of 'good' in total isolation from any of its descriptive functions. Moreover, when 'good' is used purely descrip-

41. Id. at 43 .

42. Id. at 44 .

43. S. Touluin, An Examination of the Place of Reason in Ethics 40-41 (Cambridge, 1950). 
tively, it can no longer be made to perform its special evaluative functionnamely, to commend.44 Thus, the Oxford philosophers do not simply deny that ethical utterances are judgments capable of being true or false. They deny that ethical or evaluative utterances can be simply translated into naturalistic "is" statements. Their arguments are designed to prove that such translations do violence to the ways in which evaluative utterances are in fact used.

Let us recall, once again, their basic methodological principle: To be clear about what, e.g., goodness is, is to be clear about the ways in which the word 'good' is used in our language. An examination of these uses shows, according to them, that 'good' does not name a property: that in evaluative utterances the word is used to commend; and, further, that there are empirical criteria for providing a justifying ground for commending specific classes of things. For instance, the criteria for a good strawberry are different from the criteria for a good automobile; but the word 'good' in 'good strawberry' and in 'good automobile' is univocal. When we utter the sentences 'This is a basket of good strawberries' and 'This is a good automobile,' anyone who understands the word 'good' (evaluative) understands that the sentences are being used to advise that the basket of strawberries and the automobile be chosen. This understanding does not presuppose familiarity with the criteria for good strawberries (being ripe, red, sweet, large, juicy, firm, etc.) or for good automobiles (safe, economical, durable, etc.). Thus, in the assertion that this is a good automobile, the word 'good' is not simply a shorthand for 'safe, economical, durable, etc.' If it were, say the Oxford analysts, then the sentence 'This is a good automobile' would be equivalent to the sentence 'This is an automobile and it is safe, economical, durable, etc.' If this latter sentence is to qualify as a naturalistic "is" sentence, then none of its extralogical vocabulary is an evaluative term. But then the naturalistic sentence cannot be equivalent to the original evaluative sentence; for the original sentence is used to evaluate or commend, while the naturalistic sentence can be used only to describe. Nor is the word 'good' the name of some nonnatural value property; for if it were, we could not use the sentence 'This is a good automobile' to commend the automobile; we could only succeed in saying that it has a certain value property, and this again, is to describe and not to evaluate. Evaluation and description are very different linguistic activities.

The Oxford philosophers' distinction between the prescriptive or commendatory meaning of 'good' and other evaluative words and the empirical

44. R. M. Hare, The language of Morals 118-26, 147, 150 (Oxford, 1952). 
criteria for their application is very similar to Stevenson's "second pattern of analysis." Stevenson also maintains that the evaluative meaning, for instance, of 'good' in 'good strawberry' and 'good automobile' is univocal. What the intuitionists call the "good-making characteristics" and what the Oxford analysts call the criteria Stevenson calls the "rich and varied descriptive meanings for the ethical terms, in addition to emotive meaning." Stevenson's "emotive meaning" corresponds to the Oxford analysts' "commendatory use."

There are, then, these three fundamental conclusions about which the Oxford analysts and Stevenson agree: ethical or evaluative words are not simply descriptive or simply prescriptive; however, the prescriptive (commendatory, emotive, etc.) meaning of these words is primary; ethical or evaluative words, in their primary sense, are not names of properties or attributes, either natural or nonnatural. The differences between the Oxford analysts and Stevenson are chiefly in their method of philosophizing. The Oxford analysts eschew philosophical theories. They would reject, for example, such philosophical theories of meaning as "the meaning of a sign is the disposition to arouse certain kinds of psychological responses" (C. L. Stevenson and C. W. Morris); "the meaning of a sentence is the method of its verification" (Vienna Circle); "a sentence is cognitively meaningful if, and only if, it is either empirically confirmable or logically certifiable" (later positivism and Logical Empiricism). The Oxford philosophers operate on the principle that the most direct and obvious way to be clear about concepts is to elucidate the ways in which they are used. Indeed, they maintain that unless we are clear about the concepts in the language we actually use, we cannot be clear about concepts we may wish to introduce in a reconstructed language.

In order to forestall misunderstanding, it must be pointed out that the Oxford analysts use the word 'use' in a technical way. How a concept is used is not discovered by simply observing the ways in which people do talk. The uses of a word are elucidated by describing their logical relations with other concepts. For example, if the logician wishes to define the word 'number' as this word is used by mathematicians, he has to observe the actual use mathematicians make of mathematical statements about numbers. Or, if an analytical jurist wishes to elucidate the phrase 'legal right,' he has to observe the ways in which statements about legal rights are used by judges and lawyers. He has to notice how the concept of legal right is related to other concepts, e.g., privilege, immunity, duty. He has to observe what entailments are warranted within legal discourse among statements containing 'right,' 'duty,' 'privilege,' 'immunity,' and the like. How wide a description 
of these relations is called for depends upon what puzzles we are trying to clear up. The foregoing extensive report of H. L. A. Hart's views is a case in point. According to the Oxford analysts, the philosopher differs from the plain man not in having any privileged insights into the nature of things, but in having achieved clarity by cultivating sensitivity to the contours and nuances of the language within which philosophical perplexities arise and must be resolved.

This conception of philosophy entails the rejection of normative ethics. Traditionally, normative ethics has sought rationally grounded moral rules of conduct. Differences have existed as to the nature of the rational grounds of morality because of differences as to what reason is. The Oxford analysts, agreeing with other non-cognitivists, deny that any justification grounded in reason can be meaningfully required for adopting ultimate norms. Ultimate moral commitments are decisions, not cognitions. ${ }^{45}$ Compare two hypothetical situations. In one of them, we are faced with choosing between two different theories about the physical world. To say that they are two different theories is another way of saying that the two theories will not agree in all the predictions and explanations they give. This means, in turn, that in principle there would be facts we could cite for justifying our choice of one of the theories, or neither, if neither theory accounted for the facts.

Suppose now that we are faced with a choice between two rival moral codes. Again, to say that they are two different moral codes is to say that they give different answers to the question "How should I live?" For, if they give the same answers to this question, we would have to recognize that they are in substance identical and only verbally different formulations. The choice of one of the rival codes involves the making of an ultimate decision. There is, of course, a difference between decisions based upon careful considerations and decisions made haphazardly. For the purpose of our illustration, let us assume that our choice of one of the rival codes was carefully considered. We reflected long and in our cooler moments; we took into account all the facts to the best of our knowledge; in the light of our past experience, we compared the kind of life we would live by one of the codes with the kind of life we would live by its rival. Having done all this we found that we prefer one of the two ways of living. We were committed to the moral code enjoining that way of living. Everyone would admit that such a decision is rational and not capricious or perverse. But it is conceivable that two people might arrive at different decisions after having gone through these careful considerations. How can we say that at most one of them is rationally justified? We

45. See, e.g., Hare, op. cit. supra, note 44 at 69 et passim. 
cannot; for, by hypothesis, each has made a rationally grounded choice. The basic mistake of traditional normative ethics has been the belief that there is a higher criterion for judging ultimate commitments which are rational in the above sense. According to Oxford philosophers, there are good reasons for making ultimate moral commitments; but these good reasons are not objective in the sense that traditional normative ethics would have it. Ultimate moral choices, although based on cognitions, are themselves not cognitions but decisions. And the moral principles which are the linguistic correlates of these decisions are not descriptions of scientific or metaphysical states of affairs. They are injunctions as to how to live. This is the fundamental reason why it is proper to classify the Oxford analysts as non-cognitivists.

As in the case of Stevenson and the logical positivists the non-cognitivism of the Oxford philosophers does not prevent them from uttering normative injunctions. Moral exhortation is one thing. Philosophical analysis is something else. Moral exhortation is not the proper function of a philosopher in the role of a philosopher. Like everyone else, the non-cognitivists, too, have moral convictions. What needs to be emphasized, however, is that on noncognitivist views these moral convictions are not objectively true statements describing scientific or metaphysical facts.

The extrusion of normative ethics from philosophy makes a difference to ethical jurisprudence. If normative ethics is not a theoretical science, the validity of legal norms cannot be established by "higher" objective norms discovered by recondite philosophical investigations. In particular, the rejection of normative ethics amounts to a wholesale removal of natural law theories from jurisprudence.

Let us recall that natural law theorists are ultimately in search of a consistent way of deriving the "ought" from the "is." They seek to do this in such a way that the objective validity of one and only one ethical code would follow as a corollary. These theories are overtly or covertly premised upon the assumption that there is such a thing as the nature or essence of man. This premise coupled with the premise that man ought to live in accordance with that essence implies that there is one and only one correct way to live. This amounts to believing in the possibility of normative ethics. Even though some Oxford philosophers countenance the passage from the descriptive ("is") to the prescriptive ("ought"), 46 this is not enough to sustain natural law. All Oxford philosophers agree that there is no "nature of man" in the sense just described, and therefore that normative ethics is not possible. This is the root of their quarrel with natural law.

46. E.g., S. Hampshire, Fallacies in Moral Philosophy, 58 Mind 466 (1949) and Toulmin, op. cit. supra, note 43 . 
Even a sophisticated defense of natural law such as that by A. P. d'Entrèves is not immune to this objection. Professor d'Entrèves ${ }^{47}$ concedes the force of Hume's and Kant's objections to deducing the "ought" from the "is." He thinks that the difficulties they point out can be avoided by following Giambattista Vico's suggestion that the "is" (verum) and the "ought" (certum), the element of fact and the element of authority, are inseparably fused in every law. This would circumvent the need to deduce the one from the other. But the problem remains in a different form. It now becomes the problem of showing how the element of fact supports the element of authority. Does the fact that the Latin paterfamilias would have very strong feelings against the English common law in the matter of testaments prove that the authority of the law is invalidated? What is the relation of these very strong feelings to what "reason" reveals as to the comparative claims of family duty and individual freedom? What if an English paterfamilias had very strong feelings diametrically opposed to the feelings of his Latin counterpart? Let us grant, for the sake of the argument, that if we look close enough we will find a purpose (a value) or a congeries of purposes that every law is intended to realize. But there are laws intended to implement Nazi values and laws intended to implement humane values.

For my part [d'Entrèves writes], I believe that in every human society, in fact in "human nature" itself, there are certain ultimate standards or values which determine approval or disapproval, assent or dissent; and I believe that it is these same values that determine our judgment as to whether a law is "just" or "unjust": in other words-to use a very ancient language that seems perfectly appropriate at this point-whether we are bound in conscience to obey it or not. To ascertain such values may be thought a modest-or an immodest-undertaking. Yet I think that, failing all other ways, such an undertaking is well worth attempting, and may even in the end lead us to a much greater amount of agreement than we might expect. ${ }^{48}$

If this is what d'Entrèves's defense of natural law comes to, I do not see that it is in any way different from what the non-cognitivists say. They, too, are willing to entertain the hypothesis that, upon careful consideration, every man might make identical fundamental moral commitments. But I have been assuming all along that the point of natural law theories is not this hypothesis. It is, rather, that whether people do agree on morals or not, there is a set of moral principles which they ought to accept, and that what these principles are can be objectively established. This claim alone would give content to the first basic tenet of natural law theories, namely, to the

47. 1 Natural Law Forum 5 (1956).

48. Id. at $45-6$. 
tenet that normative ethics is a science. In matters of science there are criteria entitling us to say that even though a certain individual or group disbelieves a certain statement, the evidence is such that he or the group ought to believe that statement. We do not wait for universal agreement before we feel that we are justified in making this judgment. I do not see that d'Entrèves has succeeded in showing that analogous judgments can be made in morals. The non-cognitivists argue that they cannot. The Oxford non-cognitivists argue this point by trying to show that the logic of the language of morals is radically different from the logic of the language of science.

The Oxford rejection of normative ethics has a second consequence for ethical jurisprudence. Philosophers of the Oxford persuasion would not be too happy with the generality of the central question of ethical jurisprudence. As it is usually formulated, that question is: What is the ideal or what are the ideals which we ought to realize through law? They would rather prefer to ask less general questions: What sort of law ought we to pass when faced by a more or less definitely specifiable situation X? According to Stephen Toulmin, for instance, such a question can be morally answered on two grounds alone: (a) That we ought to do $Y$ in situation $X$, because this is what some principle of the moral code of the society in which situation $\mathbf{X}$ exists demands; or (b) We ought to do $\mathrm{Y}$ because that is most conducive to the welfare of the others in the community. ${ }^{49}$ We cannot, Toulmin insists, ask why we should give (a) or (b) as an ultimate good reason, for to give an ultimate good reason is to give either (a) or (b). By way of interpolation, let me suggest that (b) is more fundamental than (a). Otherwise we would have difficulty in explaining the fact that we sometimes approve moral rebels in a given society. The moral prophet's exhortations derive their authority from the fact that they are proposals made in the name of an ideal transcending both the merely personal preferences of the moral prophet and the already existing moral rules. Let me further suggest that, upon close examination, (b) may be found to be an analytic presupposition of the concept of morality. That is to say, it may be that to be moral entails to live by (b). Whether this is so or not can be determined only by a careful examination of the ways in which we use the word 'moral,' a task which I cannot undertake here. If it should be true that (b) is analytically related to the concept of morality, then it would follow that Y's being conducive to the welfare of others in situation $\mathrm{X}$ is a logical and not just a causal reason why $\mathrm{Y}$ is our duty. The logic, however, would be imbedded in our linguistic uses. As philosophers we would simply make explicit what these uses are.

49. Toulmin, op. cit. supra, note 43 at 156 . 
This is an altogether different conception from the one according to which the job of the philosopher is to discover, by exercising his reason, ultimate norms woven into the fabric of reality. It is this latter sense of objectivity of ultimate norms that Oxford philosophy eschews. Once this is understood, the Oxford philosophers would not deny that there is objectivity in morals in the sense that there are criteria for justifying moral utterances. What they would deny is that these criteria are discovered by "metaphysical insights" or "rational intuitions" or by empirical science.

\section{IV}

Now we come to the Neo-Kantians. I think two commitments constitute a sufficient condition for classifying an ethical philosopher as a Neo-Kantian. First, he must hold that there is a single principle which is the categorical imperative of conduct, where by 'conduct' is meant activity capable of being selective and reflective. Second, he must hold that this principle is demonstrably rational and the method of demonstration is purely philosophical and without empirical admixtures. ${ }^{50}$ H. J. Paton ${ }^{51}$ and C. I. Lewis 52 are Neo-Kantian in ethics, but beyond the fact that they satisfy the sufficient conditions of Neo-Kantianism they have hardly anything else in common. Paton accepts Kant almost literally. Lewis is a naturalist in value theory and he takes far-reaching exceptions to certain fundamental Kantian doctrines. Furthermore, his manner of demonstrating the categorical imperative of rationality and his statement of the imperative itself are very different from Kant's.

Lewis has said that "valuation is always a matter of empirical knowledge. But what is right and what is just, can never be determined by empirical facts alone." 53 In short, value judgments are distinct from ethical judgments. The former can be analyzed in empirical terms; the latter cannot. Lewis agrees with naturalists that 'good' can be defined empirically and that value judgments are empirically true or false. All this he argues in great detail and very plausibly in An Analysis of Knowledge and Valuation. However, he says that 'right' cannot be defined empirically; that correspondingly, judgments of obligation, as distinct from judgments of valuation, "can never be determined by empirical facts alone." Some critics have said that

50. A corollary of this is that obligation words are not to be defined in empirical terms.

51. The Categorical Imperative (Chicago, 1948).

52. An Analysis of Knowledge and Valuation (Open Court, 1946); "The Rational Imperatives" in VIsION AND ACTION (Sidney Ratner ed., Rutgers, 1953). Lewis' most recent book on ethics is The Ground and Nature of the Right (Columbia, 1955).

53. An Analysis of Knowledge and Valuation 554 (Open Court, 1951). 
Lewis has placed himself in an untenable position. The gist of the charge is this: Lewis divides all judgments into analytic (and a priori) and synthetic (and a posteriori). He explicitly denies the existence of synthetic a priori judgments. Now judgments of valuation are taken care of. They are said to be empirical, hence synthetic. But how about judgments of obligation? Not all of these are analytic. 'No rule of action is right except one which is right in all instances, and therefore right for everyone,' is analytic, according to Lewis. But is 'Truth-telling is right' also analytic? If not analytic, and not synthetic (empirical) because it is a judgment of duty, what is it? 54 Lewis has yet to publish his work on Ethics. My own prognosis is that he will be able to show that his critics have somehow missed the point of what he is trying to say. But prognosis aside, his position in his publications to date is something like this.

In An Analysis of Knowledge and Valuation ${ }^{55}$ Lewis says that there is a connection between the intrinsically good and the morally imperative, but 'good,' meaning 'useful for conducing to satisfaction,' is something different from 'good' meaning 'morally justified.' In his more recent paper, "The Rational Imperatives," he tells us what the categorical imperative of conduct is:

The basic imperative is . . . simply that of governing oneself by the advice of cognition, in contravention, if need be, to impulsions and inclinations of feeling. . . . The most comprehensive imperative of rationality may be called the Law of Objectivity: so conduct your deliberate activities as to conform them to the objective actualities cognitively signified by your representational experience, and not by reference to any impulsion or solicitation exercised by the affective quality of experience as felt. . . . This Law of Objectivity may be otherwise put: conduct yourself with reference to those future eventualities which cognition advises that your activity may affect, as you would if the effects of it were to be felt at this moment of decision, with the poignancy of the here and now realized, instead of the less poignant feeling which qualifies representation of the future and possible. ${ }^{56}$

Lewis says that the basic rational imperative cannot be proved by appeal to some other imperative. Otherwise that other imperative would be basic. The demonstration that the basic imperative cannot be repudiated rationally is dialectical. 57

54. M. G. White, Value and Obligation in Lewis and Dewey, 58 Prros. Rzv. 321 (1949). See also A. I. Melden, On the Method of Ethics, 45 Journal of Prinosopmy 169 (1948); R. Browning, On Professor Lewis's Distinction between Ethics and Evaluation, 59 ETHIcs 95 (1949).

55. At 552.

56. "The Rational Imperatives" in Vision AND ACtion 158.

57. Lewis's argument on this point is very compact. In what follows, I have tried to spell out what I think Lewis has in mind. 
Consider the utterance of Metrodorus of Chios, an ancient skeptic: "I deny that we know whether we know anything or whether we know nothing. I say that we do not even know what is ignorance and what knowledge; that we have no knowledge whether anything exists or nothing does." 58 There is a contradiction-in-use here. Metrodorus is using his utterance to make some kind of cognitive claim. Otherwise he is talking just to hear himself talk. But if what he says is true, he is in no position to use his utterance for making a cognitive claim of any sort, because his cognitive claim conflicts with what the utterance says. It says that no one, including Metrodorus, is in a position to make cognitive claims of any sort. This is not a purely formal contradiction. It is, instead, an incompatible opposition between what Metrodorus' utterance says and his using that utterance to make a cognitive claim on his own behalf.

A similar difficulty confronts those who would deny the basic imperative of rationality. Lewis's formulation of that imperative is: Govern yourself by the advice of cognition. For purposes of illustration, let us state the first person singular version of this imperative: (a) I ought to govern myself by the advice of cognition. The denial of (a) is: (b) I may abstain from governing myself by the advice of cognition.

To see the difficulty, notice the following points. First, the denial of a normative statement is normative. This fact is easy to show. Assume that 'A ought to do $\mathrm{X}$ ' is normative. Its denial, ' $\mathrm{It}$ is not the case that $\mathrm{A}$ ought to do $\mathrm{X}$ ' is equivalent to 'A may abstain from doing $\mathrm{X}$.' Assume also that 'A ought not to do $\mathrm{X}$ ' is normative. Its denial 'It is not the case that $\mathrm{A}$ ought not to do $\mathrm{X}$ ' is equivalent to 'A may (is permitted to) do $\mathrm{X}$.' But the permissive 'may' and 'may abstain from' are definable in terms of denial and 'ought.' Therefore, if 'A ought to do $X$ ' and 'A ought not to do $X$ ' are normative, so are their denials. These facts hold also in the case of universal normatives such as 'Everybody ought to do X,' 'Nobody ought to do $X$.' Their respective denials are 'Somebody ought not to do $X$ ' and 'Somebody ought to do X.' Therefore (b), the denial of Lewis's basic rational normative, is normative.

But this is a normative utterance implicated in a contradiction like that of Metrodorus. In adopting (b), I have adopted a normative rule which does not acknowledge the obligatoriness of any rules. If I do not recognize it as obligatory to heed the advice of cognition in governing myself, my conduct cannot be subject to the critique of objective rightness. Objective rightness requires the distinction of right and wrong. But a necessary condi-

58. Crcero, Qunestiones Acadrmicae II, 23. 
tion of the objective right whether it is a question of prudence or of justice, is that whatever is objectively right should be cognitively warranted. Objective rightness has to take account not only of the moral worth of the agent's intention but also of the intention's cognitive validity. (Lewis defines the intention of an act as all the consequences which the doer expects will follow from the act.) By adopting (b), I have in effect adopted a rule which makes it not obligatory that I criticize my conduct as prudent or imprudent, just or unjust. In short, by adopting (b), I have adopted a rule of obligation which says that I may refrain from acting by rules of obligation.

Otherwise put, the denial of (a), Lewis's basic rational imperative, is equivalent to the assertion of (b). But he who denies (a) (i.e., asserts (b)) nevertheless assumes (a) in his denial of it. For if $I$ assert (b) not on the advice of cognition (i.e., without obeying or assuming (a)), my rule is no more than a gratuitous ejaculation. If I assert (b) on the advice of cognition, I am assuming the very rule that $I$ have denied in my denial of (a). The contradiction is between the attitude of adopting (b) and what (b) says. I am saying that it is not the case that I ought to govern myself in accordance with normative rules, and to say this $I$ am using a normative. So that there is, after all, at least one normative which I recognize, whereas if what it says is so, $I$ have no business recognizing normatives.

The gist of this dialectical argument is that no rational being can rationally repudiate norms exhorting rationality.

If my reading of him is correct, Lewis's conception of the rationality of moral principles accomplishes the following: when he says, at the end of An Analysis of Knowledge and Valuation that "What is right and what is just, can never be determined by empirical facts alone," Lewis has, I take it, no intention of invoking synthetic a priori connections or supernatural or otherwise nonnatural properties of duty and right. What is right and what is just can never be determined by empirical facts alone because the conceptions of right and duty are analytically related to rule-governed behavior, and the justification of rule-governed behavior is not a matter of empirical fact but of dialectical proof. He argues nonempirically (dialectically) for the objectivity of universal imperatives of conduct, but insists that the application of the imperatives analytically requires empirical knowledge.

Now it is impossible to state the consequences of Neo-Kantianism in general for jurisprudence. The sufficient conditions which I have specified for classifying an ethical theorist as Neo-Kantian leave untouched detailed commitments which are much more crucial for analytical and ethical jurisprudence. Paton's type of Neo-Kantianism has exactly the same consequences for jurisprudence as Kant's ethical theory, for Paton never deviates from 
Kant. To students of jurisprudence the Kantian position in jurisprudence is well known. Repetition here would be gratuitous. But a "Neo-Kantian" like Lewis has a very different story to tell.

Lewis's value theory is thoroughly naturalistic. But he makes a sharp distinction between value concepts (good, bad) and obligation concepts (right, just, obligatory). From what he has said to date, it would seem that Lewis would disagree with naturalists who propose empirical definitions of obligation-words. The analytical jurists who are interested in Lewis's theory of obligation will simply have to wait, like the rest of us, until he publishes his book on Ethics. So will the student of ethical jurisprudence have to wait. But some things are already clear. Lewis will certainly make room for normative ethics and he will take as more basic the concept of the morally just as against the legally just. Most philosophers would recommend to students of jurisprudence a careful study of whatever Lewis has to say.

The student of jurisprudence who becomes interested enough in these issues will find a vast literature in which, with great skill and in great detail, the various positions which I have sketched have been criticized and defended. This literature is growing daily. And, if the non-philosopher is bewildered by this embarrassing wealth of disagreement in contemporary ethical theory, he may be reassured by the fact that some of the ablest contemporary philosophers are devoting at least part of their time to the issues we have been discussing and that a good deal of progress has been made already toward clarifying many of the perplexing questions in ethical theory. 